\title{
Acts and dispositions: A reconsideration of the Act Frequency Approach
}

\author{
ALOIS ANGLEITNER \\ University of Bielefeld, FRG \\ ANDREA I. DEMTRÖDER \\ University of Münster, FRG
}

\begin{abstract}
The Act Frequency Approach (AFA) proposed by Buss and Craik was summarized and critically reviewed on the basis of a German replication study using six interpersonal traits each with 100 translated acts. The six traits studied were dominant, gregarious, agreeable, submissive, aloof, and quarrelsome. The internal structure of these categories was examined via multiple prototypicality ratings. It was demonstrated that many acts are highly prototypical for more than one category. The manifested categorical structure was tested by gathering retrospective act reports about performance and frequency of exhibiting each of these 600 acts using a sample of 213 adults. Aggregation of the acts according to their prototypicality key yielded reliable subscales. The validities obtained on the basis of the 25 highly prototypical acts were slightly higher compared with those of the 100 act set, as well as the sets with lower prototypicality. The validity gradient proposed by Buss and Craik was found using selected personality scales as well as global self-ratings and peer-ratings on some of the respective trait terms. In general, the results of the German study replicated the findings of Buss and Craik.
\end{abstract}

\section{THE ACT FREQUENCY APPROACH (AFA): THEORETICAL BACKGROUND AND EMPIRICAL METHODS}

\section{Introduction}

The Act Frequency Approach (AFA) suggested by Buss and Craik (1980, 1981, $1983 a, b, c, 1984)$ is based on the summary view of traits. To say that someone is dominant means that, over some fixed period of observation, this person has shown

Correspondence concerning this article should be addressed to: Alois Angleitner, University of Bielefeld, Department of Psychology, Postfach 8640, D-4800 Bielefeld 1, Federal Republic of Germany. 
a high frequency of dominant acts. These acts may be quite heterogeneous, but they are all considered to be manifestations of a given trait. An example of such an act is ' $\mathrm{He} / \mathrm{she}$ talked a great deal at the meeting'.

For Buss and Craik (1984, p. 245), 'acts are the basic constituent elements of the behavioral world as objects are of the inaminate world'. That means that dispositions or traits are seen as natural cognitive categories and that acts can be aggregated into these categories in a manner similar to the categorization of physical objects.

Following the ideas of Rosch $(1975 \mathrm{a}, \mathrm{b})$ concerning object categories, act categories can be analysed with regard to their internal cognitive structure as exemplified in:

(1) Single category membership in the sense that one given act is judged as being a prototypical example for the category. Different acts as members of a given act category vary along the continuum of prototypicality, ranging from high (good examples) to low (peripheral, poor examples).

(2) Multiple category membership in the sense that one given act may be judged as belonging to more than one category. According to Zadeh, Fu, Tanaka and Shimura (1975), category borders are seen as 'fuzzy', in that peripheral acts of one category may be low prototypical members of another, semantically close category.

The act frequency view also postulates that multiple act composites, so-called act trends, and not single acts are the basis for inferences and predictions of a trait.

Buss and Craik have documented the usefulness of the AFA for ten traits, including quarrelsome, agreeable, dominant, submissive, gregarious, and aloof. For each of these traits, using student samples, 100 acts were nominated. In locating these acts, Buss and Craik used an act nomination procedure. Subjects were asked to think of people they know who possess the given trait and to list examples of those people's behaviours.

The internal structure of act categories was determined by rating the prototypicality of each act with respect to the category for which it was nominated, following Rosch and Mervis's (1975) procedures. Retrospective self- and spouse-reports about the performance and frequency of each act were also gathered. Based on these retrospective act reports the manifested dispositional structure in the form of averaged base rates for each act was calculated.

The AFA postulates that dispositional assessment techniques should display higher validity for prototypical act composites compared with peripheral composites within each act category (gradient of validity). To test this proposition, Buss and Craik adopted the following procedures: For each trait category the abovementioned act reports were summed up into four composite scores. The grouping of acts was done according to their prototypicality status for the category in question. The acts were arranged into quartiles from high to low prototypicality (I $=$ highly prototypical acts, HP; IV = low prototypical acts, LP). Different sets of correlations were then compared:

(1) The number (percentage) of significant correlations between single acts and selected scales from personality inventories [Personality Research 
Form (PRF), Jackson, 1967; California Personality Inventory (CPI), Gough, 1957; Interpersonal Adjective List (IAS), Wiggins, 1979; Eysenck Personality Questionnaire (EPQ), Eysenck and Eysenck, 1968; Buss-Durkee Hostility Inventory, Buss and Durkee, 1957].

(2) The mean single act correlations (averaged over 100 acts) with some of these personality scales.

(3) The correlations between composite act trends and some of these inventory scales.

Generally, these comparisons showed that scale validities for the aggregated act scores based on the prototypicality key were superior compared to the validities using single acts as criteria. Furthermore, the validities are usually higher using more prototypical than using more peripheral act composites within each trait category (validity gradient).

Finally, it should be noted that Buss and Craik view multiple act composites as predictor and criterion variables. The AFA is concerned with the predictions of future act trends and life outcomes based on summary interpretations of past conduct (Buss and Craik, 1983c).

\section{A CRITICAL APPRAISAL OF THE AFA}

In our appraisal of the fruitfulness of the AFA we will focus our attention on the topics discussed below, and in so doing, we will underline the problems associated with this approach.

\section{The internal category structure: the issue of multiple category membership}

Buss and Craik (1986, p. 147) stated that 'although prototypicality ratings yield simple and direct indices of the differential status of acts, they undoubtly underestimate the complexity of the multiple constructs that may be used to interpret each act. In particular, some acts may be subsumed by more than one dispositional category.' To test multiple (as opposed to single) category membership of acts, Buss and Craik $(1984,1986)$ described a two-step procedure. First, subjects were instructed to sort each act into one or more categories (free categorization). Second, the same subjects were asked to rate the prototypicality of each act for the category in which it had been placed earlier.

On the basis of these categorization data, multiple category membership was shown for about 200 acts from the whole set of 800 acts. The criterion for multiple category membership was that at least 50 per cent of the judges categorized the act in more than one category. For instance, many acts were categorized as belonging simultaneously to the categories dominance and extraversion. Considerable overlap was also documented for the categories quarrelsomeness and dominance, a finding also reported by Borkenau (1986) using different empirical methods. And finally, some acts were seen as manifestations of three dispositions. Interesting asymmetries also were found in these free categorizations. From the 100 acts nominated for quarrelsome, 48 were also judged to belong to dominance. But from the 100 nominated acts for dominance, only 28 were also judged to belong to 
quarrelsomeness. Buss (1985, p. 7) interprets this finding as follows: 'These results suggest that the disposition of dominance is broader than the disposition of quarrelsomeness, which is narrower in the sense of containing fewer act members. These results also suggest that dominance bears at least a partially superordinate relationship to quarrelsomeness, and thus may be more frequently used as a reference point.'

However, this two-step procedure for assessing multiple prototypicality has some shortcomings: First, using categorization data, multiple category membership could only be expressed in percentages of subjects who sorted them into the different categories. Second, on the basis of the subsequent prototypicality ratings, multiple prototypicality ratings can be calculated only for a limited set of acts-namely, those which are sorted into more than one category in the first step of this procedure. Third, the above implies that the mean prototypicality ratings for the acts are based on different numbers of judges and comparability is restricted. These shortcomings have some implications for the reliability of this rating procedure.

To overcome these shortcomings, a method is required which permits multiple prototypicality data for all acts with respect to all categories to be obtained. Such a method would clarify the relation between each nominated act and each of the categories under consideration. For this reason, in our study multiple category membership was assessed via this form of multiple prototypicality ratings. In six subsequent steps, subjects rated the prototypicality of each of the 600 acts for each of the six categories.

It could be assumed that act overlap is due to the semantic similarity of the category terms. The more two trait terms are similar in their semantic meaning, the higher is the probability that acts are constituent elements of both of the categories (see also Borkenau, 1986). However, from the viewpoint of dispositions as natural cognitive categories, conceptualized analogous to the object domain, it follows that these multiple memberships should especially be obvious for less prototypical acts which are posited near the 'fuzzy' borders or within the transient zone between categories, whereas highly prototypical acts should be members only for one category.

\section{The manifested categorical structure: the aggregation issue, reliability, and validity}

Buss and Craik (1984) aggregated acts into composite scores according to their prototypicality key (prototypicality quartiles). They compared correlations between these composite scores and relevant personality scales with correlations found between the personality scales and single acts. They demonstrated that prototypicality aggregation is superior to single acts in yielding higher validity coefficients. This result is to be expected because some theoretically guided aggregation in multiple indices based on different observations usually results in higher reliability and validity coefficients as compared to single indices (Epstein, 1979, 1980; Jaccard, 1974). However, the critical test of the claim that aggregation according to the prototypicality key yields higher reliability and validity is to compare this form of aggregation with some other. Broughton (1984) compared different personality scale construction strategies including a rational and a prototype strategy, where the prototype strategy turned out to be superior in yielding higher validities. Similarly, we proposed to compare aggregation using all 
100 acts, which could be interpreted as a rationally constructed item sample, with aggregation using prototypicality. Our hypothesis is that the act lists aggregated according to their highest prototypicality yield higher validities than either the whole 100 -item act lists or the act samples with lower prototypical acts. Another possible form of aggregation would be to sample items according to their corrected item total correlation but, according to the theory underlying the AFA, the manifested inter-act correlational structure is conceptually irrelevant and may be used only for descriptive purposes.

In their validity studies, Buss and Craik used selected scales from personality inventories, global self-ratings, as well as the IAS (Wiggins, 1979). The personality scales were chosen on their face validity. Buss and Craik (1984, p. 273) state: 'From the perspective of the act frequency approach, a personality scale or another assessment instrument is expected to forecast the relative frequency of topographically dissimilar acts occurring over a period of time, all of which are considered to be manifestations of a given dispositional category (e.g., dominance).'

To summarize the relations between the act scores and selected PRF and CPI scales, the act categories dominance, gregarious, and quarrelsome were highly predictable. Furthermore, the postulated validity gradient based on prototypicality was found. However, the act categories submissive, aloof, and agreeable were not highly predictable and only for the highest prototypicality quartiles were sufficiently high validity coefficients found (see Buss and Craik, 1984). In a more extensive study with self- and observer-reported act data and personality scales (EPQ: Extraversion; CPI: Sociability; PRF: Affiliation; and IAS: Extraversion), the above findings for the act category extraverted were replicated. However, the magnitudes of the correlations were lower for the composite act trends based on the observer data than for the composites based on the self-report data.

Concerning global ratings, Buss and Craik (1981) reported quite low correlations between dominant act composites and a self-rating on dominance, compared to correlations with dominance as measured by personality scales (PRF,CPI). Similar results were published by Buss (1981), in which the correlations using the multiple indices of the IAS with the act reports were compared with correlations by using personality inventory scales. Buss and Craik (1983c) explained the missing convergence between observer impressions and act trend data by pointing out that for observer impressions additional behavioural information and also other components have some influence. They mentioned, for example, physical appearance, ascribed role status, cognitive schemata, and gender. Observer impressions do not correspond highly with act performances because observers in particular are influenced by this information. According to Buss and Craik, ratings are open to this kind of bias, whereas the retrospective self- and peer-reports on the performance or frequency of behavioural acts are not.

Using the same selected scales from the PRF, the replicability of the validities found by Buss and Craik in the realm of the personality scales will be tested. Compared with the personality scales, we expect that the validities in the realm of the self- and peer-ratings of personality adjectives to be lower. The superiority of the PRF could be explained by (1) the higher reliability of this instrument, (2) a certain amount of similarity or partial overlap between act- and item-formulations, (3) a similarity between the instruments in style and format, and (4) the fact that the act lists are based on multiple indices, whereas adjective data are mostly based 
on single ratings (except when adjective scales like the IAS are used). The act lists and the personality scales are also similar with regard to the judgement tasks for the subjects, whereas the basis for the judgement in the adjective ratings is a more complex task. In contrast, answering an act list or a personality item list seems to be a more concrete, and therefore easier, task for the subjects.

However, following the summary view of traits, we suppose that the postulated pattern of correlations as well as the gradient of validity must appear in adjective ratings. Further, Buss and Craik $(1980,1981)$ view the appearance of the validity gradient as support for the notion of dispositions as natural cognitive categories, organized around prototypes. From this perspective, validity studies using self- and peer-ratings can be seen as the most preferable data sources for pointing out the generalizability of the results found on the basis of personality scales.

According to Buss (1981) and Buss and Craik (1983c), the less predictability as well as the failure of the gradient of validity for some of the categories may have been due to an endorsement or activity trend which biases the data. To clarify this assumption we reanalysed our data using a correction formula. For each subject the act trend index per category was determined as the proportion of the total act output (over all 600 acts). According to Buss and Craik, this correction could be interpreted as an aquiescence correction, but could also reflect that some people may be somewhat more active and therefore produce more acts compared with more passive people.

In the present study, empirical data concerning reliability and the proposed validity gradients based on personality scales as well as on self- and peer-ratings will be reported and compared.

\section{THE GERMAN REPLICATION OF THE AFA}

The act lists, consisting of 100 acts for each of the following six traits, were translated into German (by Borkenau): aloof, gregarious, dominant, submissive, quarrelsome, and agreeable.

\section{Semantic similarity ratings}

The semantic similarity of the six trait adjectives was judged by a new sample of 27 paid student subjects (16 males, 10 females; for one person this information is missing). They had to rate the similarity of the pairwise comparisons of all possible pairings of the six traits using seven-point rating scales $(1=$ very similar, $4=$ neutral, 7 = opposite).

\section{Prototypicality ratings}

The prototypicality of these acts was judged by 20 paid student subjects ( 10 males, 10 females). Each act, in male and female phrasing, was judged for its prototypicality with respect to each of the six trait categories (multiple prototypicality rating). The instructions, which had originally been developed by Rosch and Mervis (1975) and adapted by Buss and Craik (1980) for the act domain, as reported in Buss and Craik (1984), were used. A seven-point rating scale was 
employed with 1 indicating low prototypicality and 7 indicating high prototypicality. The assignment of subjects, acts, and traits was completely randomized to avoid sequential effects. The acts were printed on cards. Subjects had to sort these cards into one of seven boxes. Each box represented one point of the rating scale. The sorting was done on six consecutive days; in each session the prototypicality of all 600 acts related to one category was rated.

\section{Retrospective reports on act lists and self- and peer-ratings}

Following Buss and Craik's procedures, subjects indicated whether they had performed this act (performance). If they indicated yes, they were required to give frequency estimates (seldom, sometimes, often). No retrospective time-frame was specified for the act reports. For the 600 acts, retrospective self-ratings were gathered from a sample of 213 subjects (mostly students or academics of which 110 were males and 103 were females and none of whom had taken part in the prototypicality study). These subjects were also administered the German version of the PRF (Stumpf, Angleitner, Wieck, Jackson and Beloch-Till, 1985), and a selfand a peer-rating on adjective lists was collected from each member of the sample. Subjects were free to determine who should make the peer-rating; no level of familiarity was specified. The adjective lists consisted of 35 interpersonal traitadjectives, including the six traits mentioned above. Ratings were done on fivepoint rating scales, with 'Mostly' (1) to 'Not at all' (5) as endpoints of the scales. Subjects had to rate how correctly their behaviour could be summarized by the trait terms across different situations.

\section{RESULTS}

\section{Cross-cultural comparisons}

If we want to evaluate the AFA by using Buss and Craik's acts, it is a prerequisite to show that these acts are culturally transferable. A detailed presentation of crosscultural comparisons will be found in Angleitner, Buss and Demtröder (1988). From these comparisons we concluded that the use of the translated act lists is justified.

\section{Semantic similarities}

In Table 1 the mean semantic similarities for the different trait pairs are shown. The traits agreeable and gregarious, as well as dominant and quarrelsome, were judged to be quite similar, whereas the adjective pairs submissive-dominant, quarrelsome-agreeable, gregarious-aloof were seen as quite opposite in their semantic meanings. The ratings replicate the semantic similarity data published by Borkenau (1986).

\section{Prototypicality: the issue of multiple category membership}

We examined multiple category membership at different levels of analysis: (a) the descriptive level of single acts, (b) the level of the 100 nominated acts per category, 
Table 1. Mean semantic similarity ratings among the six trait descriptive adjectives

\begin{tabular}{lccccc}
\hline Adjective & Dominant & Quarrelsome & Aloof & Submissive & Agreeable \\
\hline Quarrelsome & 2.81 & & & & \\
Aloof & 4.70 & 4.63 & & & \\
Submissive & 6.67 & 5.81 & 4.11 & & \\
Agreeable & 4.12 & 6.26 & 4.26 & 4.15 & \\
Gregarious & 4.19 & 5.30 & 6.04 & 4.59 & 1.96 \\
\hline
\end{tabular}

Note: $1=$ very similar, $4=$ neutral, $7=$ opposite. $N=27$ students.

and (c) the level of intercorrelations of mean prototypicality ratings, using each set of the 100 acts as well as the total 600 nominated acts.

\section{Rater agreement}

At the level of the 100 nominated acts per category, the interjudge agreement for the prototypicality ratings was similar to that reported by Buss and Craik. The Cronbach alpha values for the six traits varied between 0.84 (for dominance) and 0.93 (for quarrelsomeness) for the total sample of judges $(N=20)$.

\section{Results at the level of single acts}

Table 2 shows several acts nominated for dominance and quarrelsomeness, and their multiple prototypicality ratings with respect to each of these two categories. Two different aspects of these multiple ratings are apparent: First, multiple dispositional membership was found for highly prototypical acts, which means that some acts are highly central for more than one category. For example, the dominant act (No. 8) 'I hit someone who annoyed me' was rated as a good example for dominance as well as for quarrelsomeness (4.60) vs 5.07). These overlaps between highly prototypical acts were found for all categories. However, there were some differences in magnitude between them. Some of these overlaps were

Table 2. Some examples of multiple prototypicality: dominant and quarrelsome acts

\begin{tabular}{lllll}
\hline & \multicolumn{3}{c}{ Dominance } & \multicolumn{2}{c}{ Quarrelsomeness } \\
& $\mathrm{M}$ & $\mathrm{SD}$ & $\mathrm{M}$ & $\mathrm{SD}$ \\
\hline Dominant acts & & & & \\
90. I became angry when my suggestion was & & & & \\
$\quad$ not accepted & 4.85 & 1.50 & 4.90 & 1.86 \\
76. I refused to acknowledge that I was wrong & 4.75 & 2.07 & 4.95 & 1.88 \\
8. I hit someone who annoyed me & 4.60 & 2.04 & 5.07 & 2.11 \\
28. I used my fists in order to get my way & 4.50 & 2.14 & 5.05 & 2.09 \\
20. I blamed others when things went wrong & 4.20 & 2.04 & 5.90 & 1.29 \\
& & & & \\
Quarrelsome acts & & & & \\
53. I insisted on having the last word in the discussion & 4.85 & 2.01 & 5.85 & 1.31 \\
14. I refused to change my mind on the issue & 4.50 & 2.04 & 4.75 & 2.05 \\
7. I contested my grade vigorously with the teacher & 4.35 & 1.87 & 5.35 & 1.50 \\
8. I insisted that the group go to my favourite & & & & \\
restaurant & 4.25 & 1.80 & 5.50 & 1.10 \\
100. I raised my voice in the debate & 4.20 & 1.94 & 4.90 & 1.65 \\
77. I bragged about my grade-point average & 4.55 & 2.14 & 2.95 & 1.85 \\
\hline
\end{tabular}

Note: $1=$ low prototypicality, $7=$ high prototypicality. 
also reported by Buss (1985). In his study, item No. 8 was sorted to the dominance category by 70 per cent of the sample and also to quarrelsomeness by 85 per cent. Second, some acts possess a higher prototypicality for an 'alien' category than for the category for which they had been nominated. For example, the quarrelsomeness act (No. 77) 'I bragged about my grade point average' was rated as a fairly good example for dominance, but as relatively low in prototypicality for its "own" category. Similar results were also found for the other categories.

For each act the category for which the mean prototypicality was highest was determined and Table 3 shows the distribution of the acts according to their highest prototypicality ratings. For example, of the 100 gregariousness acts, 25 reached their highest prototypicality for dominance, 1 for aloofness, 3 for quarrelsomeness, and only 54 for gregariousness (the category for which they originally had been nominated).

Table 3. Distribution of the acts according to their highest mean prototypicality ratings

\begin{tabular}{lcccccc}
\hline $\begin{array}{l}\text { Nomination } \\
\text { Category }\end{array}$ & Dominance & Quarrelsomeness & Aighest prototypicality \\
\hline Dominance & 77 & 12 & 1 & 1 & Sloofness & Submissiveness \\
Quarrelsomeness & 37 & 58 & 4 & - & - & 8 \\
Aloofness & 14 & 2 & 82 & 2 & - & - \\
Submissiveness & 2 & 1 & 17 & 64 & 1.3 & 3 \\
Agreeableness & 4 & - & 4 & 18 & 5.5 & 19 \\
Gregariousness & 25 & 3 & 1 & - & 17 & 54 \\
\hline
\end{tabular}

Buss and Craik (1986) also found some of these 'misassignments' of acts to categories, if one interprets percentages of sortings as an index of the centrality of an act. For instance, the quarrelsomeness act 'She refused to change her mind on the issue' was sorted to the 'own' category by 60 per cent of the sample, but also to dominance by 80 per cent.

Moreover, there seems to be an asymmetric relationship between the categories dominance and quarrelsomeness insofar as a larger number of quarrelsomeness acts were also rated as central for dominance (37) than the other way round (12). Comparable results were also reported by Buss (1985) and Buss and Craik (1986).

\section{Results for the 100 nominated acts per category}

In Table 4 the mean multiple prototypicality ratings over the 100 acts for each of the six categories are shown. At this level of analysis it is also evident that high mean prototypicality for an alien category can often be found together with high prototypicality for the traits for which the acts were nominated. For instance, the mean prototypicality of the quarrelsomeness acts rated for quarrelsome (4.05) was not much higher than the prototypicality of those acts rated for dominance (3.82). Somewhat lower 'overlaps' were found between gregarious and dominance and also between gregarious and agreeable. For the other three categories there were also some slight overlaps. Furthermore, these data again replicate the asymmetric relationships between categories found by Buss and Craik (1986).

Table 4 also gives information about some categorical differences in the maximum rated prototypicality for the 'own' category. The highest prototypicality of all was found for dominance (4.54). The mean prototypicality calculated for all categories was 4.0 , a value which also represents the scale mean. 

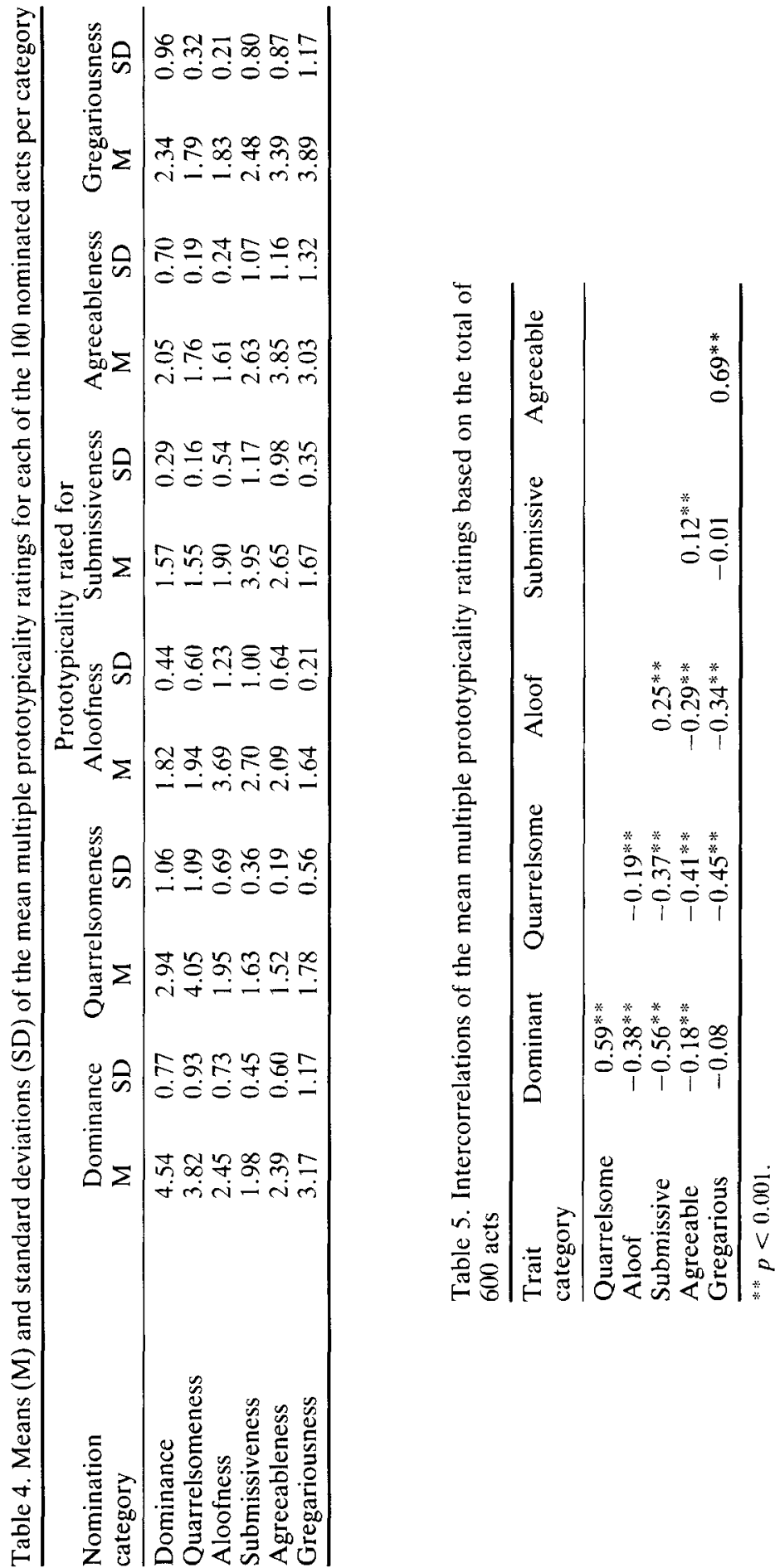


\section{Analysis of the intercorrelation matrix of the prototypicality ratings}

The correlations of the mean prototypicality ratings among the six categories based on the overall set of 600 acts yielded the following picture (see Table 5).

Multiple category membership comes into evidence as well at this level of analysis, as indicated by the positive correlations. A strong relation between the prototypicality ratings of the acts for dominance and for quarrelsome was demonstrated (0.59). A positive but somewhat smaller relation between aloof and submissive and between agreeable and submissive was also found. The strongest relation was found between gregarious and agreeable. However, the correlation between dominance and gregarious, a result found at the other levels of analysis, did not surface among these intercorrelations.

From these data it is not possible to extricate information about whether the relation is symmetric or asymmetric. For this reason, the intercorrelations for the mean prototypicality ratings of the 100 acts per category with their mean prototypicality for the remaining five other trait categories were computed (see Table 6). Besides the result that a large amount of multiple category membership exists, as demonstrated by the positive correlations, Table 6 also shows the asymmetries. For example, the correlation between the prototypicality of the dominance acts rated for dominance and their rating for quarrelsomeness yielded a value of 0.18 . In contrast, the correlation between the rating of the quarrelsome acts rated for quarrelsome and for dominant was 0.35 .

As mentioned earlier in the paper, these correlations may reflect act overlap due to semantic similarity. The correlations (Spearman's rho) between the intercorrelation matrix of the mean prototypicality ratings based on the overall set of 600 acts and the matrix of the mean semantic similarity ratings of the six trait terms yielded a value of $0.94(p<0.001)$.

\section{Aggregation: retrospective self-reported act performances and reliability}

The reliabilities of the six act lists were quite high, ranging from 0.92 for submissiveness to 0.94 for dominance, gregarious, and quarrelsome (see Table 7). The reliabilities of the act composites, aggregated according to the prototypicality key, were also impressively high and similar to the results reported by Buss (1981). For the high prototypicality quartiles the Cronbach alpha values ranged from 0.77 for submissiveness to 0.83 for agreeableness, aloofness, and dominance. The reliabilities for the low prototypical act quartiles were only slightly lower, ranging from 0.69 for aloof to 0.81 for quarrelsome.

Viewed over all quartiles per category, the reliabilities for the different categories were comparatively high, except for submissiveness which revealed the lowest values at all levels. In Table 7 the estimated reliabilities (prolongation to 100 acts using the Spearman-Brown test prolongation formula) for the highly prototypical act composites are also shown. All values were close to 1.00. And also the lowest reliability coefficient of all $(0.69$, for the lowest prototypicality quartile of submissive) could be raised to 0.90 .

\section{Validity by using personality scales}

First, we will report the correlations between the performance scores of the selfreported act composites and the selected PRF scales Dominance (Do), Affiliation (Af), and Aggression (Ag). 


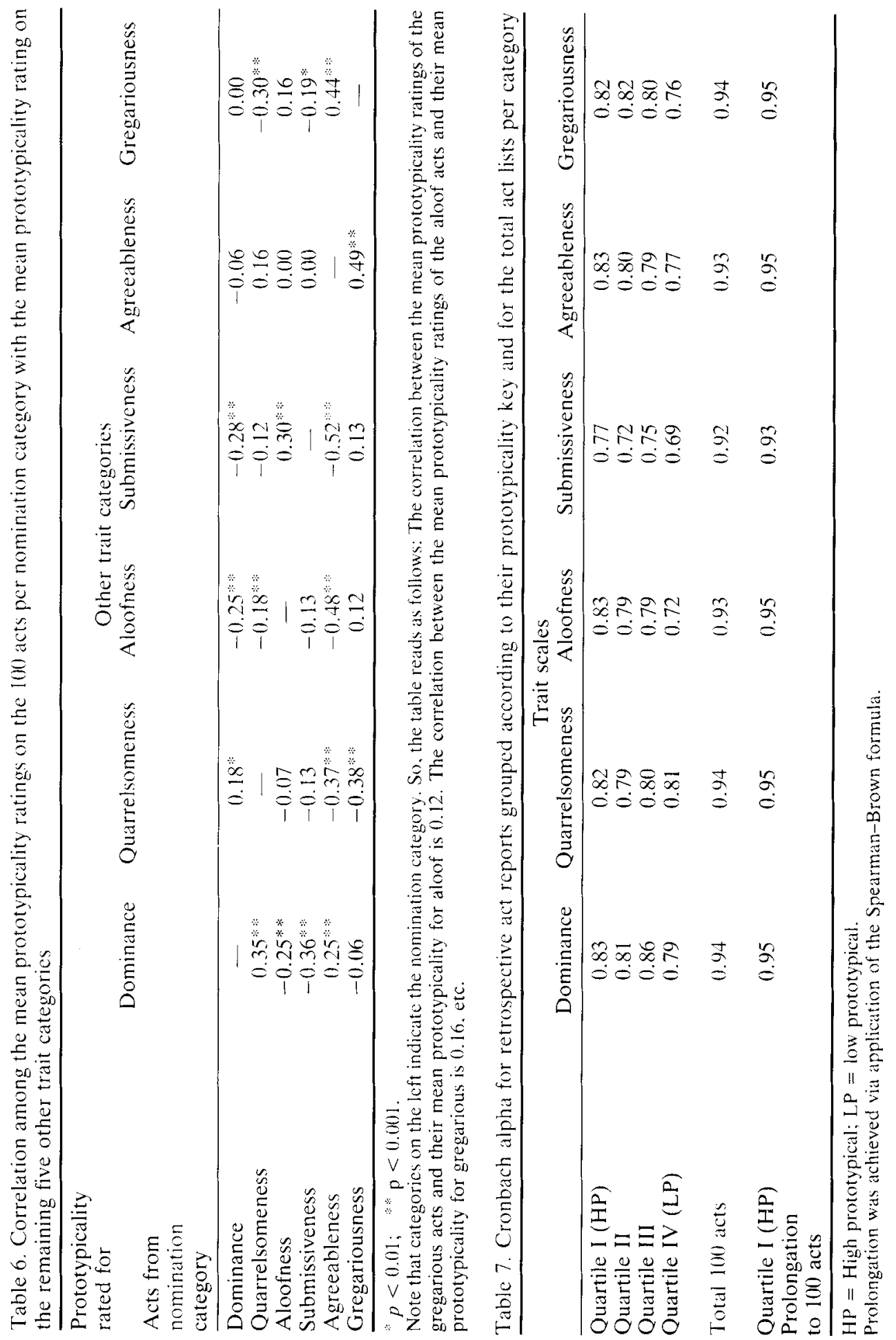


In some cases, the correlation between the appropriate predictor scales for each of the six traits and the act-trend scores based on the whole set of 100 acts or on the four prototypicality quartiles were quite impressive (see Table 8). Buss and Craik's postulate, that there exists a gradient of validity for these quartiles, was partly verified in the German study - an increase of validity was associated with higher prototypicality. The set containing the 25 acts with highest prototypicality also yielded slightly higher validities than the set of 100 acts.

Buss and Craik (1984) summarized the results of their studies including these three scales, so we can refer to their Table VI for comparisons. For the traits dominant and gregarious our predictive validities were slightly higher, but for quarrelsome they were slightly lower than those of Buss and Craik. For submissive the results were similar. For the remaining traits (aloof and agreeable) Buss and Craik's results were not clear-cut.

There is a clear difference between these six traits with respect to their predictive validity. The highest validities were found for gregarious, dominant, and quarrelsome. For the traits submissive and aloof, only the sets containing the highest prototypical acts yielded significant validities. For agreeable, the predictive validities as assessed by the PRF-Ag scale were around zero.

\section{Validity studies by using self- and peer-ratings}

Summarizing our results for the self- and peer-ratings on the six traits, the following can be stated: (a) As predicted, the overall picture of the validities for the self- and peer-ratings corresponded to the validities we obtained with the selected PRF scales (see Table 8). The highly predictable traits-dominant, quarrelsome, and gregarious - werc also predictable by means of the self- and peer-ratings. But those validities were lower than those resulting from the PRF scales. (b) In general, the postulate concerning the validity gradient of the prototypicality quartiles also held for these ratings.

\section{Validity reconsidered after application of a correction procedure}

We recalculated the validity coefficients for the prototypicality quartiles by using the corrected data sets. These recalculations changed the overall picture of our results for the unpredictable traits submissive, aloof, and agreeable. Using the PRF scales significant validities were found. On the other hand, for gregariousness, the self- and peer-ratings showed lowered validitics (see Table 9).

These changes in the validities using the corrected data sets, however, are predictable from a consideration of the correlations of the sum scores over all 600 acts with the personality scales as well as these act sum scores with the global selfand peer-ratings. These correlations (given below) were significantly positive for the selected PRF scales Af, Ag, and Do $(0.22,0.20,0.21)$. For the self-ratings. only aloof showed a significant, but negative, correlation with this index $(-0.17)$. This last result was also replicated for the peer ratings $(-0.19)$. But in addition, at the peer-rating level a significant positive correlation with gregarious $(0.32)$ and a significant negative correlation with submissive $(-0.19)$ appeared. The abovementioned correction partials out content variance-namely, individual differences in exhibiting acts rather than controlling acquiescence or other response tendencies. This conclusion is justified in view of the quite high correlation of the total multiple index of 600 acts (correction index) with the PRF scales. The PRF' scales are well 


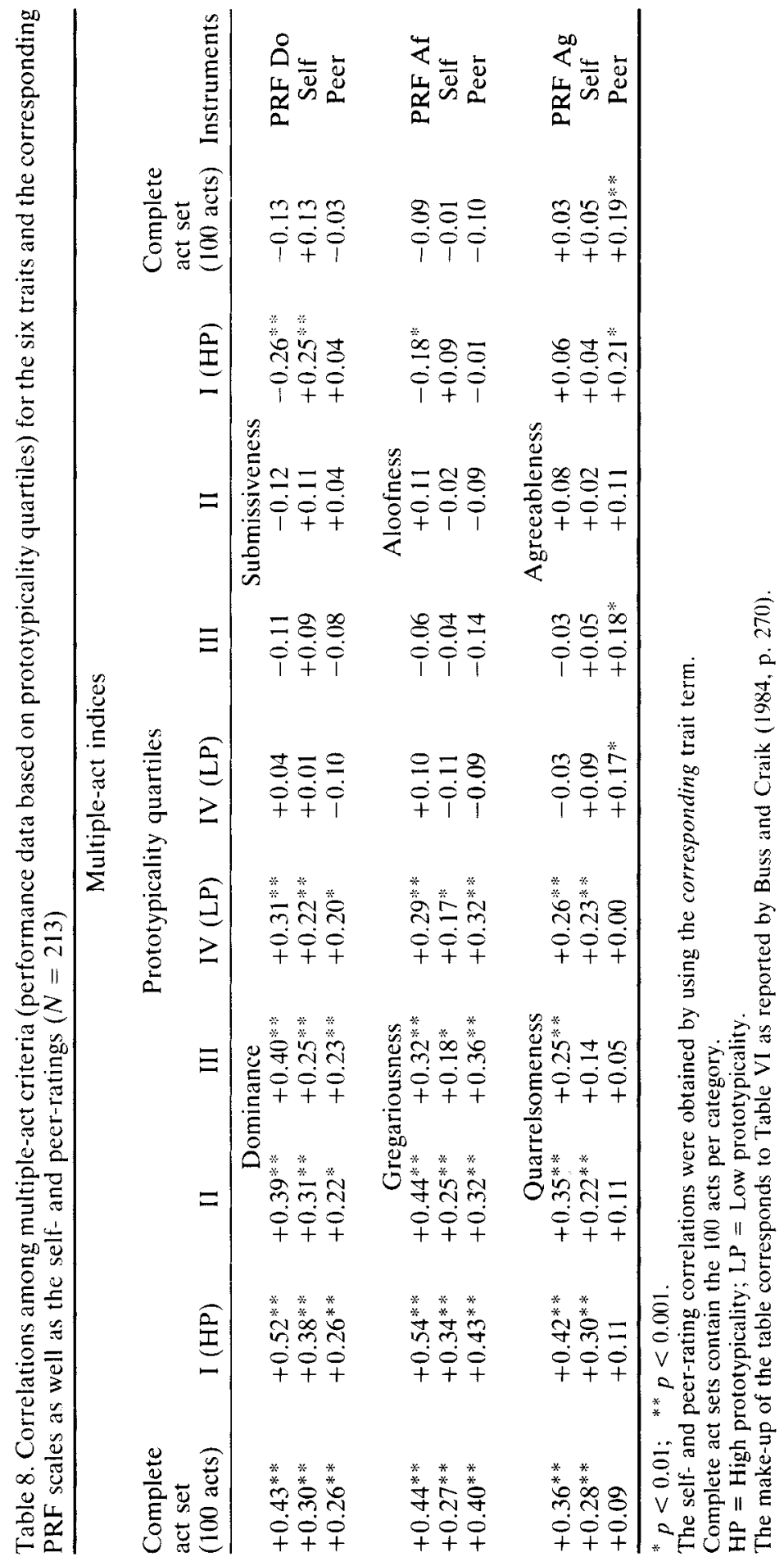




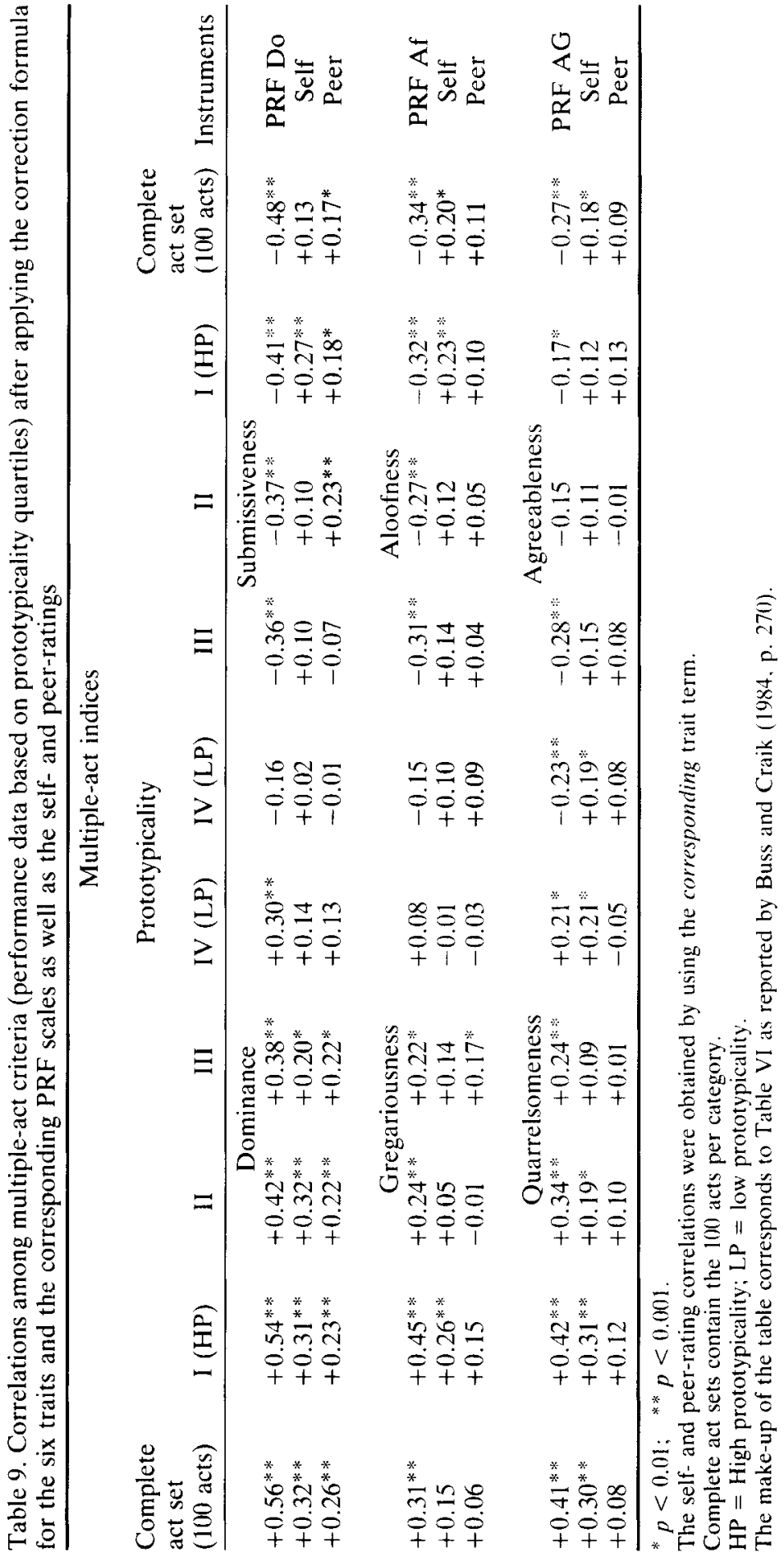


balanced with respect to their keying. Therefore, lower correlations would be expected if the correction index reflected stylistic variance or acquiescence.

\section{DISCUSSION}

In discussing our results we will first refer to the topics in our appraisal of the Act Frequency Approach.

\section{Multiple prototypicality}

Multiple category membership of acts was found at different levels of analysis. From the theoretical viewpoint of dispositions as natural cognitive categories, such multiple membership should only be obvious for low prototypical members, which are posited to lie near the fuzzy borders or within the transient zone between two categories (Buss and Craik, 1983c). However, both in our research and in Buss and Craik's there were many acts, even from the highest prototypical quartiles, which are prototypical for more than one category. One possible explanation for this finding could be the overall low level of prototypicality of the acts. In our prototypicality study, for none of the acts the positive endpoint of the scale $(7=$ 'Best example') was reached.

It may be that with the kind of nomination procedure employed by Buss and Craik not enough good examples for a trait were generated. In this procedure, subjects were asked, for example, to name dominant acts, but they were not asked to name dominant in contrast to quarrelsome acts. There may exist some highly prototypical acts which are seen to belong only to one special category, but subjects were not directly instructed to generate them.

However, we found multiple category membership for acts with prototypicality values above the scale mean of 4.0. Such acts cannot be interpreted as being low in prototypicality in the sense of being near the fuzzy borders. Furthermore, we found acts rated as an example for only one trait category and these acts did not show significantly higher prototypicalities compared to those mentioned above.

Gergen, Hepburn and Fisher (1986) argued that responses on any item of a personality scale, such as the Internal-External Control Scale (Rotter, 1975), could plausibly be used as an example for any trait term. Transferred to the behavioural domain, this suggestion implies that each act may be a member of each possible category. But there is a difference between typical inventory items and behavioural acts as defined by the AFA. An act describes a delimited behaviour, and a special social or object context in which this behaviour takes places. In this respect an act is more concrecic than normal inventory items. However, some interpretations or inferences are necessary for understanding or noticing an act. Take the quarrelsome act 'I insisted on having the last word in a discussion', 'insisted' may be interpreted differently depending on whether it is understood as being expressed verbally or behaviourally. As a result of a particular interpretation at the time of judging, subjects may see a behaviour as belonging to different categories, but such overlap should arise only for conceptually close or semantically similar categories, and not for semantically dissimilar categories. As demonstrated by the high correlation between the structure of the semantic similarity ratings and the 
structure of the multiple prototypicality ratings, act overlap was found especially for those categories which are semantically close in meaning. Therefore, our results confirm the systematic overlap hypothesis postulated by Borkenau (1986). This hypothesis states that the more two trait descriptive terms are similar in meaning, the more they refer to overlapping act universes. However, this explanation is somewhat restricted because there are always some acts that seem to belong to only one category even if the relevant categories are semantically very close.

In summary, our results showed more complexity for dispositional categories than for object categories. From our viewpoint, the idea of single category membership, which has proved to be profitable for the object domain (see Rosch, 1975a,b, 1978), is problematic when transferred to the behavioural domain. The borders of act categories seem to be 'fuzzier' than those of object categories, especially if caltegories are conceptually close.

It seems necessary to clarify the hierarchical organization of the six trait categories employed. The more prototypical an act is for a category, the higher is the probability that this act will also be seen as a member of the corresponding higher level (superordinate) category. For many categories of natural objects the middle category, called the 'basic level' by Rosch, was documented as the most useful one. Catcgories at this basic level have 'attributes common to all or most members of the category' (Rosch, 1978, p. 31). The basic level term in the natural object domain is further characterized as a term which is used more frequently in the common language. Buss and Craik (1983a) assumed that the trait terms function as basic level categorics for the personality domain. The question arises of how much variation in breadth and hierarchy is acceptable for basic level categories if one wants to interpret trait terms as basic level categories. There may be trait terms at higher (superordinate) and lower (subordinate) levels. Ihat traits differ considerably. from each other in their breadth, and that some traits are organized hierarchically was recently shown in a study by Hampson, John and Goldberg (1986).

In addition to theoretical problems, multiple category membership poses problems for dispositional assessment by the AFA where subjects' statements about act performance were aggregated into specific act trends. Before summarizing the behaviour of a person as, for example, dominant, it should he clear to which category or catcgories each act reported by the person belongs. Acts which show a clear multiple category membership should therefore be summed up to the scores of the respective categories to which the act belongs, and not only to the nomination catcigory.

\section{Aggregation principles and validation}

The two aggregation principles used yielded comparable reliability and validity. In general, the proposed validity gradient was confirmed: An increase in validity was associated with higher prototypicality. However, this finding wis not consistent across all six traits. In particular, submissive, aloof, and agreeabie were not well predicted by our measures. These traits, however, gained in predictability when the correction was applied. Furthermore, the self- and peer-rating procedures yielded, with some exccptions, comparable results to those of the personality scales, indicating that global ratings may also be conceptually appropriate. 
In our validity studies it turned out that, beyond the overall better validities of the personality scales, the higher prototypical act sets achieved better validities by use of the global self- and peer-ratings. This result seems to be in line with Broughton (1984) and Mischel and Peake (1982). The latter authors discussed the importance of temporal stability of prototypical behaviours for perceived trait consistency. We may conclude that trait ratings are probably also based on highly prototypical behaviours.

We will now discuss some more general issues of the AFA. The German replication data corresponded closely with those reported by Buss and Craik. However, these findings are restricted to this particular set of 600 nominated and translated acts. At first glance, the act nomination procedure seems to be a very easy task for subjects. However, we were not successful in using this instruction for producing sets of behavioural acts. People found it difficult to follow the instructions and frequently generated impressions or trait terms. We are also puzzled that, since the first appearance of the AFA in 1980, no one else beside the authors of the AFA has published reports using the act nomination procedure. Further research aimed at generating new act lists is needed so that the original and the new lists can be compared.

Furthermore, the reliabilities and validities based on the set of 100 acts versus prototypicality keying showed a close correspondence. If this result is replicable, then some explanation has to be offered, irrespective of the postulated conceptual irrelevance of the intercorrelations of the manifested acts. Probably all nominated acts for one trait have 'something' in common, so that even random strategies in selecting multiple act composites may be able to produce somewhat reliable and valid scales. However, one must consider that most of the data are based on selfreports. Subjects may have formed their trait impressions after or before filling out the act lists. On the other hand, there is not so much divergence between self- and peer-rating data sets. Therefore, we believe that this bias may be cancelled out by the different orders in which our subjects answered the test devices. Our conclusion is: If one is able to apply the act nomination procedure successfully one will find an item sample that may be reliable and valid for further predictions.

In general, the data concerning the AFA reported by Buss and Craik were replicated in our study. But this fresh approach of thinking and theorizing about acts and dispositions contains some unsolved problems. We hope that our results will further stimulate the thinking and theorizing necessary for this approach.

\section{ACKNOWLEDGEMENTS}

Preparation of this article was supported by a grant from the University of Bielefeld (OZ 2766) to A. Angleitner. We gratefully acknowledge the assistance of Willibald Ruch in the collection of some of the German act report data. We thank Peter Borkenau, David M. Buss, Michael Gutmann, Sarah E. Hampson, Fritz Ostendorf, Rainer Riemann, and Robert A. Wicklund for comments on a draft of this article. 


\section{REFERENCES}

Angleitner, A., Buss, D. M. and Demtröder, A. I. (1988). 'A cross-cultural comparison using the Act Frequency Approach in West Germany and the United States'. In preparation.

Borkenau, P. (1986). 'Towards an understanding of trait interrelations: acts as instances of several traits', Journal of Personality and Social Psychology, 51: 371-381.

Broughton, R. (1984). 'A prototype strategy for the construction of personality scales', Journal of Personality and Social Psychology, 47: 1334-1346.

Buss, A. H. and Durkee, A. (1957). 'An investigation for assessing different kinds of hostility', Journal of Consulting Psychology, 21: 343--348.

Buss, D. M. (1981). 'The act frequency analysis of interpersonal dispositions', Unpublished doctoral dissertation, University of California, Berkeley, CA.

Buss, D. M. (1985). 'The interpersonal categorization of acts', Presentation to the Society for Experimental Social Psychology, Chicago, IL, 18 October.

Buss, D. M. and Craik, K. H. (1980). 'The frequency approach of disposition: dominance and prototypically dominant acts', Journal of Personality, 48: 379-392.

Buss, D. M. and Craik, K. H. (1981). 'The act frequency analysis of interpersonal dispositions: aloofness, gregariousness, dominance, and submissiveness', Journal of Personality, 49: 174-192.

Buss, D. M. and Craik, K. H. (1983a). 'The act frequency approach to personality', Psychological Review, 90: 105-126.

Buss, D. M. and Craik, K. H. (1983b). 'Act prediction and the conceptual analysis of personality scales: indices of act density, bipolarity and extensity', Journal of Personality and Soicial Psychology, 45: 1081-1095.

Buss, D. M. and Craik, K. H. (1983c). 'The dispositional analysis of everyday conduct'. Journal of Personality, 51: 393-412.

Buss, D. M. and Craik, K. H. (1984). 'Acts, dispositions and personality'. In: Maher, B. A. and Maher, W. B. (Eds), Progress in Experimental Personality Research: Normal Personality Processes, Vol. 13, pp. 240-300, Academic Press, New York.

Buss, D. M. and Craik, K. H. (1986). 'The act frequency approach and the construction of personality'. In: Angleitner, A., Furnham, A. and Van Heck, G. (Eds), Personality Psychology in Europe: Current Trends and Controversies, Vol. 2, pp. 141-156, Swets and Zeitlinger, Lisse.

Epstein, S. (1979). The stability of behavior: I. On predicting most of the people much of the time', Journal of Personality and Social Psychology, 37: 1097-1126.

Epstein, S. (1980). 'The stability of behavior: II. Implications for psychological research', American Psychologist, 35: 790806.

Eysenck, H. J. and Eysenck, S. B. G. (1968). The Manual of the Eysenck Personality Inventory, Educational and Industrial Testing Service, San Diego, CA.

Gergen, K. J., Hepburn, A. and Fisher, D. C. (1986). 'Hermeneutics of personality description', Journal of Personality and Social Psychology, 50: 1261-1270.

Gough, H. G. (1957). Manual for the California Psychological Inventory, Consulting Psychologist Press, Palo Alto, CA.

Hampson, S., John, O. P. and Goldberg, L. R. (1986). 'Category breadth and hicrarchical structure in personality: studies of asymmetries in judgments of trait implications', Journal of Personality and Social Psychology, 51: 37-54.

Jaccard, J. J. (1974). 'Predicting social behavior from personality traits', Journal of Research in Personality, 7: 358-367.

Jackson, D. N. (1967). Personality Research Form Manual, Research Psychologist Press, Goshen, NY.

Mischel, W. and Peake, P. K. (1982). 'Beyond déjà vû in search for cross-situational consistency', Psychological Review, 89: 730-755.

Rosch, E. (1975a). 'Cognitive reference points'. Cognitive Psychology, 7: 532-547.

Rosch, E. (1975b). 'Cognitive representations of semantic categories', Journal of Experimental Psychology: General, 104: 192-233. 
Rosch, E. (1978). 'Principles of categorization'. In: Rosch, E. and Lloyd, B. B. (Eds), Cognition and Categorization, pp. 27-48, Erlbaum, Hillsdale, NJ.

Rosch, E. and Mervis, C. B. (1975). 'Family resemblances: studies in the internal structure of categories', Cognitive Psychology, 7: 563-605.

Rotter, J. B. (1975). 'Some problems and misconceptions related to the construct of internal versus external control of reinforcement', Journal of Consulting and Clinical Psychology, 43: $56-67$.

Stumpf, H., Angleitner, A., Wieck, Th., Jackson, D. N. and Beloch-Till, H. (1985). Deutsche Personality Research Form (PRF), Hogrefe, Göttingen.

Wiggins, J. S. (1979). 'A psychological taxonomy of trait-descriptive terms: the interpersonal domain', Journal of Personality and Social Psychology, 37: 395-412.

Zadeh, L. A., Fu, K. S., Tanaka, K. and Shimura, M. (Eds) (1975). Fuzzy Sets and Their Application to Cognitive and Decision Processes, Academic Press, New York.

\section{RÉSUMÉ}

L 'Act Frequency Approach (AFA), 'élaboré par Buss et Craik, est présenté et résumé de manière critique sur la base d'une étude allemande. Dans cette étude, pour six notions-types interpersonnelles, on traduit en allemand les 'actes-listes' américains (avec chaque fois 100 exemples de comportement par catégorie-type). Les six caractères étudiés sont: dominant, sociable, aimable, soumis, reservé et querelleur. La structure interne des catégories est étudiee grâce à de multiples estimations de 'prototypicalité'. Contrairement à ce qu'on presume (les dispositions sont des catégories cognitives naturelles accompagnées des actes du comportement, groupés autour d'un prototype théorique), on peut élaborer des croisements clairs entre les catégories, au sens où beaucoup d’actes sont tout-à-fait représentatifs de plus d'une catégorie. On enquête sur la structure manifeste des catégories grâce à des auto-évaluations rétrospectives opérées à l'aide des actes-listes (en rapport avec la réalisation d'un acte, et sa fréquence), à propos des 600 actes, auprès d'un échantillon de 213 adultes. Le regroupement des actes d'une catégorie en fonction de leur valeur prototypicale conduit à des sous-échelles fiables. Les coefficients de validité de ces sousgroupes, qui englobent 25 actes tout-à-fait prototypiques, avec des groupements caractériels, ne sont que faiblement supérieurs aux valeurs correspondant, dans les 'actes-listes', aux 100 actes respectifs ou aux sous-groupes formés par les 25 actes faiblement prototypiques. En utilisant aussi bien les groupements caractériels que les auto-évaluations (ou les évaluations par des personnes connues) se rapportant aux appellations correspondantes, le gradient de validité postulé par Buss et Craik ne peut être vérifié que pour certaines catégories de dispositions. Cela mis à part, les découvertes rapportées par Buss et Craik se confirment bien.

\section{ZUSAMMENFASSUNG}

Auf der Basis einer deutschen Replikationsstudie wird der Verhaltensaktansatz (Act Frequency Approach, AFA), entwickelt von Buss and Craik kritisch vorgestellt und zusammengefaßt. In der deutschen Studie wurden für sechs interpersonelle Eigenschaftsbegriffe die amerikanischen Aktlisten mit je 100 Verhaltensbeispielen pro Eigenschaftskategorie ins Deutsche übersetzt. Die sechs untersuchten Eigenschaften waren: dominant, gesellig, freundlich, unterwürfig, reserviert und streitsüchtig. Die internale Kategorienstruktur wurde mittels multiplen Prototypikalitätseinschätzungen untersucht. Entgegen den Annahmen von Dispositionen als natürliche kognitive Kategorien mit Verhaltensakten als Mitgliedern, 
die um einen theoretischen Prototypen angeordnet sind, konnte eine deutliche kategoriale Überschneidung gezeigt werden, in dem Sinne, daß viele Akte hoch prototypisch für mehr als eine Eigenschaftskategorie sind. Die manifeste Kategorienstruktur wurde mittels retrospektiven Selbsteinschätzungen anhand der Aktlisten (bzgl. der Ausführung und der Häufigkeit der Ausführung) für jeden der 600 Akte bei einer Erwachsenenstichprobe von 213 Personen untersucht. Aggregation der Akte einer Kategorie gemäß deren Prototypikalitätsausprägung führte zu reliablen Subskalen. Die Validitätskoeffizienten der Subskalen, die die 25 höchstprototypischen Akte umfaßten mit ausgewählten Persönlichkeitsskalen waren nur geringfügig höher, verglichen mit den entsprechenden Werten der Aktlisten zu je 100 Akten oder den Subskalen gebildet aus den 25 niedrigprototypischen Akten. Der von Buss and Craik postulierte Validitätsgradient konnte, sowohl bei der Anwendung der Persönlichkeitsskalen als auch bei globalen Selbst- und Bekanntenbeurteilungen für die entsprechenden Eigenschaftenbezeichnungen nur für einige der Dispositionskategorien gezeigt werden. Darüberhinausgehend ließen sich die von Buss und Craik berichteten Befunde gut replizieren. 